\title{
Acción Cívica y prensa en la última dictadura. "Operativos solidaridad" y la búsqueda de consenso en Bahía Blanca
}

\author{
Civic Action and press in the last dictatorship. "Operatives Solidarity" \\ and the search for consensus in Bahía Blanca
}

Ana Belén Zapata aymarazapata@yahoo.com.ar

http://orcid.org/0000-0003-0058-9102

Facultad de Filosofía y Letras; Universidad de Buenos

Aires/ Instituto de Desarrollo Humano; Universidad

Nacional de General Sarmiento (Argentina)

\section{Resumen}

En este artículo analizaremos algunas de las prácticas que las fuerzas militares emplearon durante la dictadura militar argentina (1976-1983) a los fines de legitimarse y construir consenso social. En concreto reconstruiremos las tareas de "acción cívica" realizadas por distintas fuerzas en la jurisdicción de la subzona 51 y en particular el rol que asumió la prensa local frente a los episodios denominados "Operativos solidaridad" que tuvieron lugar durante 1977, 1979 y 1981. Sostenemos que en la búsqueda por construir consenso, las fuerzas militares requirieron de alianzas y cooperación con distintos sectores de la sociedad civil. En ese sentido, nos concentraremos en particular en el análisis de la cobertura mediática que realizó el diario La Nueva Provincia de Bahía Blanca sobre dichos eventos. 
Palabras clave: acción cívica; dictadura; consenso; medios de prensa.

\begin{abstract}
In this article we will analyze certain practices that military forces used during the military dictatorship (1976-1983) in order to legitimize themselves and build social consensus. Specifically, we will reconstruct practices of "civic action" carried out by different forces in the jurisdiction of sub-zone 51, and in particular the role assumed by the local press in relation to these episodes called "Operative Solidarity" that took place during the years 1977, 1979 and 1981. We consider that in the search to build consensus the military forces required alliances and cooperation with different sectors of civil society. Therefore, we will concentrate in particular on the analysis of the media coverage made by the newspaper La Nueva Provincia of Bahía Blanca about these events.
\end{abstract}

Keywords: civic action; dictatorship; consensus; press.

Esta somera reseña no refleja ni con mucho la acción cívica a cargo de una de las más importantes ramas del Ejército Argentino en el área de su jurisdicción aunque tiene la virtud de dar una idea aproximada de la magnitud del esfuerzo asumido por el arma en su afán de colaborar en el desarrollo económico-social del país, especialmente de sus zonas marginadas. La Nueva Provincia (editorial), 29/05/1977

En este artículo analizaremos algunas prácticas que se desarrollaron dentro del marco de tareas de "acción cívica" realizadas por fuerzas militares en la jurisdicción de la sub-zona 51(1) y el rol que asumió la prensa frente a estos episodios durante la última dictadura militar en Argentina. Nos centraremos en particular en el análisis de la cobertura mediática del diario La Nueva Provincia sobre los eventos denominados "Operativos solidaridad".

Sostenemos que estos eventos fueron utilizados por las fuerzas militares para crear consenso y legitimarse frente a la sociedad civil en alianza y cooperación con ciertos sectores de la misma. El sector empresarial fue uno de ellos y, dentro del mismo, la empresa de medios más importante a nivel local, el diario La Nueva Provincia (en adelante LNP) propiedad de la familia Massot (2). Desde estas tareas de "acción cívica" las fuerzas procuraron establecer vías de control social, en particular de control poblacional y migratorio. También trascender y consolidar 
una presencia material y simbólica en el espacio público barrial desde la creación de espacios verdes icónicamente ligados a la idea de "solidaridad" como valor discursivo al cual ligaban estos eventos. Este ideario estuvo vinculado a sentidos católicos y nociones del "bien común" en términos nacionales y patrióticos. Desde los "Operativos solidaridad" (en adelante OS) se buscaron resultados visibles y rápidos que pudieran incidir en la cotidianeidad barrial e impactar en la opinión pública.

Al momento se han abordado varias aristas vinculadas al análisis del rol de los medios de prensa en regimenes autoritarios. $Y$ en particular el rol de los distintos medios nacionales durante la última dictadura militar (Blaustein y Zubieta, 1998; Franco, 2002; Varela, 2005; Montero, 2007; Borrelli, 2008; Saborido y Borrelli, 2011). Para el ámbito local se ha analizado la relación de la prensa y las tareas de acción psicológica, falseamientos, encubrimientos de información y construcción de un "enemigo interno", aunque poco se ha trabajado respecto al rol de la prensa ante el accionar de las fuerzas para sostener el régimen y legitimarse en sociedad; acciones que, en efecto, convivieron dentro de la superficie redaccional. Como sostiene Daniel Lvovich:

\begin{abstract}
no existe régimen político alguno que haya logrado mantener su estabilidad y pervivencia empleando exclusivamente métodos coercitivos (...). En tal sentido, la historiografía sobre las dictaduras europeas del siglo XX coincide en señalar que en dichos regímenes se aplicaron políticas específicas para mantener sus apoyos originales e incluso ampliarlos, alcanzando a sectores originariamente considerados hostiles (2006: 2).
\end{abstract}

En este sentido se podrían interpretar las palabras de lbérico Saint Jean, a la sazón gobernador de facto de la provincia de Buenos Aires, que en abril de 1976 intervenía frente a los intendentes de la provincia sosteniendo que resultaba imperioso "propender el consenso y participación de toda la comunidad en la acción de gobierno [aunque] con absoluta prescindencia de connotaciones de carácter político" (Canelo, 2005: 411).

\title{
"Acción cívica" en el V Cuerpo de Ejército
}

Desde reconstrucciones institucionales, historiadores militares del $\mathrm{V}$ Cuerpo de Ejército trazaron antecedentes de prácticas de "acción cívica" en tareas que se remontaban a coyunturas fundacionales (3). Enrique Cesar Recchi -coronel retirado y asesor de Estudios Históricos del Comando V Cuerpo de Ejército- rastreaba desde el siglo XIX la "acción cívica" 
del Ejército, entendida como un conjunto de tareas de infraestructura, construcción y reparación del espacio público. Para la segunda mitad del siglo XX el autor enumeraba las "obras de bien público llevadas a cabo por el Ejército en la Patagonia"; incluía entre ellas la obra de "bajada de la Rinconada, en la ruta 40" realizada durante 1944, además de un racconto de acciones que incluían desde construcciones de puentes, gasoductos, limpieza de desagües y trabajos viales hasta la construcción de capillas o centros asistenciales entre mediados de los años 40 a mediados de los 70 .

Sin embargo, la "acción cívica" como parte del funcionamiento operativo regular del Ejército quedó regulada a través del Reglamento de Operaciones de Asuntos Civiles (en adelante RC19-1), publicado en 1966. Se la definía como:

\begin{abstract}
el empleo del personal y medios militares en proyectos que resulten de utilidad para la población civil, en todos sus niveles, en actividades tales como educación, obras y servicios públicas, agricultura, transporte, comunicaciones, salud pública y otras que, además de contribuir al desarrollo social y económico, realzan o consolidan el prestigio de las fuerzas armadas ante la población (4).
\end{abstract}

En términos generales, también se encontraban sus antecedentes dentro del Programa de Asistencia Militar (PAM) de los años 60, en la "civic action" de la administración de Kennedy que implicaba que las fuerzas armadas se presentaran ante la sociedad como asistentes para el bienestar de la ciudadanía, asumiendo la función de enmendar "las injusticias sociales" (Mazzei, 2012: 148).

Según reconstruye Alicia Divinzenso (2016) los planes de "acción cívica" en Argentina comenzaron a formalizarse recién desde 1963 e implicaron distintas prácticas del Ejército para vincularse con la sociedad civil, en pos de generar impresiones positivas del accionar militar desde "misiones sociales" generadoras de disciplinamiento (5) y legitimación. En una doble vía de acción, si bien se consideraba que dichas obras mejorarían el nivel de vida de la población, las tareas también eran concebidas como "uno de los principales medios de prevención contra la 'subversión', pues estrechaba el vínculo entre civiles y militares buscando instalar imágenes positivas de la labor, objetivos y valores castrenses entre los ciudadanos" (Divinzenso, 2016: 79). De esa forma, quedaba vinculada la "acción cívica" con la Doctrina de Seguridad Nacional. 


\section{¿Qué fueron los "Operativos Solidaridad" desde los medios locales?}

El papel de periodistas, reporteros gráficos y empresas de medios ante prácticas de "acción cívica" había quedado asentado en la reglamentación castrense. Reglamentación desde la cual se inscribía que el lugar específico que ocuparían los medios de prensa era el de dar la mayor difusión a los eventos de este estilo. En las Directivas del Comandante en Jefe de Ejército por las cuales se solía actualizar el RC 19-1, aparecían algunos de los señalamientos respecto de cómo, desde la prensa, se debían comunicar los planes de "acción cívica". Desde estas directivas se preveía explícitamente la utilización de los medios de comunicación locales para difundir dichas acciones. En efecto "la difusión de las actividades no solo estaba a cargo de la unidad militar que las llevaba adelante, sino que las directivas estipulaban que se debía informar al Comando en Jefe del Ejército una reseña de las obras realizadas. Para ello se pedía explícitamente material fotográfico y periodístico para replicar la difusión de las obras realizadas" (Divinzenso, 2016: 72).

En la prensa bahiense hasta septiembre de 1977 la palabra "operativo" venía teniendo asociación con el adjetivo "antisubversivo". Por esos años eran numerosas las páginas dedicadas a mostrar casi rutinariamente escenas de la violencia política desde editoriales de LNP Ilamando a una violencia estatal y "ordenadora" contra la "subversión" (Zapata, 2014b). LNP desempeñaba un papel activo en la creación de imaginarios tendientes a apoyar la llamada "lucha antisubversiva". Sin embargo, a mediados de septiembre resultó novedoso un titular que anunció un "operativo", pero ahora secundado por la palabra "solidaridad".

Los OS fueron tres y estuvieron espaciados entre sí, cada dos años. Lo cual nos proporciona una pauta respecto del esfuerzo por sistematizar este tipo de prácticas, lograr cierta normalización y habituar a la población a las mismas. El primer OS comenzó el 13 de septiembre de 1977, el segundo el 5 de mayo de 1979 y el tercero el 26 de noviembre de 1981. Estos operativos conformaron tareas de "acción cívica" del V Cuerpo de Ejército desde las cuales la fuerza buscó ligarse con actores civiles específicos. Desde esa impronta se realizaron acciones de diversa índole que comprendieron, desde la asistencia social y sanitaria hasta tareas de urbanismo e infraestructura, pasando por actividades de control poblacional y provisión de documentación en barrios -por lo general- ubicados en la periferia de la ciudad.

El primer OS se extendió por varios días. Desde LNP se le dio amplia cobertura mediática, evidenciada en los cuatro días en los que el tema ocupó las principales páginas del diario. Se llevó a cabo en el barrio Noroeste y fue protagonizado por dos de las distintas fuerzas de incidencia operativa en la ciudad, por efectivos del comando $V$ Cuerpo de Ejército y del Comando de Operaciones Navales. Dependió del teniente coronel Rubén José Ferretti y tuvo la 
participación de efectivos navales, así como también de representantes de otras entidades públicas y privadas como funcionarios del Ministerio de Obras y Servicios Públicos, de DEBA, ENTEL, Gas del Estado, Ferrocarriles Argentinos, Viabilidad Nacional y Provincial, Municipal, Dirección de Migraciones y Zona Sanitaria I. En cuanto al ámbito privado, las asociaciones civiles y del ámbito empresarial que participaron fueron: la Corporación del Comercio y la Industria, la Asociación de cooperativas argentinas, Compañía YPF, Compañías Shell, ISAURA y Fundación ESSO, Empresa Furfuro y Jauge, Cámara de la Construcción, Banco Cooperativo Agrario; de Galicia y Buenos Aires; de Italia y Río de la Plata; de Londres y América del Sud; de Río Negro y Neuquén; Español del Río de la Plata; Francés del Río de la Plata; Granadero Argentino; Holandés Unido; Banco del Sud; Nacional de Desarrollo; Popular de Rosario; Regional Sureño y City Bank. Junto con la Cámara Regional de Compañías Financieras y el Club de Leones Palihue.

Durante diez días consecutivos se desarrollaron tareas diversas bajo el lema "sin voluntad no hay solidaridad, sin solidaridad no hay convivencia". De acuerdo a las crónicas, los efectivos se habían propuesto mejorar cuestiones del orden médico-asistencial (vacunación masiva de niños) y cuestiones infraestructurales como instalaciones de energía eléctrica, nivelación y rellenado de calles, marcación de veredas, alcantarillas y construcción de plazoleta. Desde la prensa se prometían tareas de colocación de telefonía en la sociedad de fomento del barrio, colocación de grifos comunitarios, el reacondicionamiento del servicio público de electricidad, el mantenimiento de líneas y redes de todos los servicios y la tramitación de documentación legal a extranjeros.

Las fuerzas militares lanzaron un comunicado que se distribuyó entre los vecinos del barrio y luego fue publicado por el diario, en él se podía leer la idea de la solidaridad ligada a un ideario patriótico en el lema: "El esfuerzo que todos hacemos tiene un nombre, solidaridad, que significa comunión de ideas para lograr el bien común de todos los argentinos y la grandeza de la patria" (6).

Para lograr una exhaustiva cobertura del evento, las fuerzas invitaron a los periodistas de LNP a recorrer todo el perímetro afectado por las distintas tareas desde los vehículos de las fuerzas. Se buscó generar cierto impacto visual con fotografías que acompañaron las crónicas y amplificaron la difusión de los hechos.

Sobre las actividades cercanas a la Escuela nro. 37 de O'higgins 1700, el diario relataba: "las actividades docentes en tanto, se desenvolvían normalmente y en el recreo de las 11 previa campanada, los alumnos se encontraron con una escuela cubierta de personas trabajando y una fisonomía que iba tomando otro color" (7). El establecimiento -según el diario LNP- se había visto "gratamente 'invadido' por los conscriptos". Acto seguido, la imagen que replicaba el 
medio era la de un Ejército benévolo, altruista, servicial y en una clara actitud de cuidado y protección de los sectores más vulnerables de la población, se señalaba en la nota que: "en tanto en el interior, dos médicos oficiales de Ejército y Marina, respectivamente, procedían al control sanitario de la población infantil, detectando y previniendo problemas de salud" (8).

La cobertura de este evento incluyó también un recuadro titulado "Repercusión". Allí el diario presentaba la mirada de los/las destinatarios de estas acciones. La imagen que construía era, no solo de pleno consenso ante las actividades, sino también de agradecimiento, "colaboración" y "hermandad". Desde esas palabras LNP construía la escena para sus lectores:

\begin{abstract}
La primera jornada de apoyo a la comunidad -teniendo en cuenta que aún restan muchas horas de trabajo sincronizado- tuvo una repercusión inmediata: el efecto de las mejoras se fue visualizando a lo largo de la barriada olvidada por la obra pública y los vecinos manifestaron de diversas formas su colaboración. Sobre el mediodía, como símbolo quizás de la hermandad reinante, un camión conducía a soldados y marineros rumbo al batallón en busca del consabido 'rancho' y una mujer se acercó llevando unos panes -simplemente eso- al grupo que había estado trabajando cerca de su casa. Todos los ojos decían: gracias (9).
\end{abstract}

Este relato concluía ilustrado desde una fotografía al pie donde se veían laboriosos marinos abriendo un paso a nivel, trabajando manualmente con picos y palas en las calles del barrio. El epígrafe de la foto hablaba de "sincronización y un gran estado de ánimo" de "presencia y ganas de hacer" como características centrales de este operativo que había reunido "a las Fuerzas Armadas y la comunidad en un nuevo intento por un logro mancomunado, es este caso, mejorar la situación de los vecinos del Barrio Noroeste" (10).

Este operativo incluyó también acciones como la construcción de una plazoleta bautizada bajo el nombre de "Solidaridad" en referencia al operativo desde el cual se la creaba. De esa forma, simbólicamente las fuerzas militares conseguían cierta trascendencia en el espacio barrial desde una marca concreta y perdurable. Esta plazoleta fue delimitada por setenta árboles perimetrales y acondicionada con juegos para niños, según las crónicas. La creación de este espacio daba cuenta de la intencionalidad de incidir en la cotidianeidad, en las formas de sociabilidad y en la urbanización del barrio.

Independientemente de la propia cobertura del diario, la presentación oficial del operativo ante la sociedad bahiense estuvo signada por una reseña que el mismo $\vee$ Cuerpo de Ejército envió al medio. Este informe detallaba la relevancia del trabajo que venían realizando las fuerzas "junto a instituciones públicas y privadas" a la vez que reconocía el importante papel de "los 
múltiples comerciantes, inclusive del barrio, que donan muchos artículos al concurrir a adquirirlos, y las expresiones de adhesión y colaboración recibidas, sintetizan la solidaridad de la comunidad bahiense en busca de la unidad definitiva de todos los argentinos" (11). Desde este informe no solo se instalaba la idea de un consenso social expresado en palabras como "adhesión", "colaboración", "solidaridad", sino que también el V Cuerpo se arrogaba la interpretación de las intencionalidades sociales de la "comunidad bahiense" (presentada como un todo uniforme) bajo la caracterización de la búsqueda por la "unidad nacional".

En el primer balance público de este operativo, el coronel Rafael Benjamín de Piano afirmaba que habían querido dar "un ejemplo de lo que es la solidaridad y proporcionarle un alivio a las carencias que padecen los pobladores de este sector. Sin actitudes solidarias resulta difícil cristalizar algo" (12). De Piano también encontraba múltiples responsables en las "deficiencias" halladas en el barrio o la "zona de operatividad solidaria", como se lo denominaba. Si bien señalaba que "todos somos responsables autoridades de todos los niveles y es nuestro deseo que gran parte de la población se acerque a ver esto" (13). De Piano apuntaba hacia los años de ineficacia del poder político y "burocrático". Desde los OS los militares "solidarios" se presentaban a sí mismos marcado la diferencia ante las situaciones de vulnerabilidad encontradas. En conferencia de prensa el coronel De Piano junto al capitán de navío Francisco Guillermo Cobos, manifestaron que "sin espíritu solidario nada se puede hacer y criticó a los trámites burocráticos que impiden que los vecinos obtengan elementos mínimos" (14).

El segundo OS se realizó en el barrio Villa Libre, durante los primeros días de mayo de 1979. Observamos en este caso una intencionalidad de reformular el lazo social con una de las barriadas populares que había sido centro de organizaciones muy politizadas en los años previos al golpe de Estado de marzo de 1976 en Bahía Blanca. Por aquellos años, en Villa Libre se habían formado distintos núcleos de militancia obrera/sindical/estudiantil filiadas con la tendencia peronista y anclada en unidades básicas y en distintos focos de militancia sindical ligados con la Juventud de Trabajadores Peronistas (JTP). El diálogo de este operativo con las acciones de militancia social de esos sectores políticos -cuyos principales referentes para ese entonces ya habían sufrido de diversas formas la represión dictatorial con persecución, detenciones en los centros clandestinos de la ciudad, torturas etcétera (15)- resultaba evidente en el tipo de acciones que incluyó este OS. Muchas de las cuales se vincularon con la asistencia a niños y jóvenes del barrio, similares a las realizadas allí por la militancia en el contexto pre-dictatorial. Asimismo, este tipo de acciones se vincularon con las políticas sociales de la dictadura y las actividades en el marco del Año internacional del niño. En función del mismo, y en el marco del segundo OS, se anunciaba que a los niños de Villa Libre se les iban a repartir bebidas gaseosas e iban a participar de distintos eventos recreativos como funciones 
cinematográficas, festivales llevados a cabo por la banda militar y otros entretenimientos. Resulta necesario analizar estas actividades para la niñez y no perderlas de vista en tanto formas singulares de control y "utilización del tiempo libre, más ligada al disciplinamiento social que a la recreación" (Osuna, 2017).

El segundo OS además, fue presentado por LNP como la expresión de una "movilización cívico-militar" integrada por el teniente coronel Hugo Delmé, el mayor Andrés Rebechi, Juan Giuliani, el teniente primero Jorge Igounet y el jefe de Operaciones coronel Carlos Garay. Algunas actividades del operativo tuvieron lugar entre las calles Charcas, Sarmiento, Rawson y Pringles donde se ofrecieron servicios de clínica médica, ginecología y obstetricia, pediatría y odontología. También un camión hospital del $V$ Cuerpo se encargó de acercar médicos y enfermeras del Hospital Militar Bahía Blanca de la municipalidad y de la provincia.

Estos operativos tuvieron un sentido específico en el marco del relegamiento de la política partidaria pregonada por el poder dictatorial, que buscaba acentuar el control municipal y sub nacional de la gestión territorial. Como sostiene Canelo,

\begin{abstract}
el municipio fue un eslabón fundamental del Plan Político del régimen: como instrumento político del control territorial y poblacional 'capilar' característico de la dictadura; como espacio autorizado para la participación de una 'ciudadanía municipal', a-política y de alcance local; como laboratorio de la apertura política, y como ámbito de gestación de la 'dirigencia natural' argentina. La ciudad era considerada 'el ámbito fundamental de la participación de una 'ciudadanía municipal', apolítica y de alcance local, basada en la 'convivencia solidaria' entre vecinos (2015).
\end{abstract}

En este orden de cosas, resulta entendible que en la cobertura de los operativos se hablara del consenso logrado fundamentalmente desde la "organización vecinal" como subtitulaba el diario uno de los apartados. Allí se señalaba que "luego de tomar contacto con las autoridades militares, los vecinos se han organizado mediante jefe de manzana, a efectos de reunir las inquietudes y necesidades que se vayan planteando diariamente a la Sociedad de Fomento y Liga de Madres del lugar" (16). Se acentuaba la importancia del nivel municipal y de asociaciones civiles/vecinales locales como espacios donde se definía la política social "despartirizada" y llevada a cabo por "entidades intermedias" (Canelo, 2015). El segundo OS, nuevamente marcó la articulación entre las fuerzas militares locales, el sector privado y diversas empresas de la zona. El Ejército se colocó -junto a los sectores empresarios participantes- en un lugar de "compromiso solidario" hacia las comunidades menos beneficiadas de la ciudad. 
Los cronistas del diario fueron transportados de forma organizada en las mismas camionetas y vehículos del Ejército, para la usual recorrida del lugar en pos de la cobertura. Por la mañana los corresponsales de LNP habían sido llevados "en un ómnibus especial, en compañía del mayor Juan José Guiliani (...) al lugar de la concentración de la conducción del Operativo, el club Villa Libre, en calle Fournier."(17)Y más tarde los periodistas, fotógrafos y camarógrafos de LNP recorrieron la zona en camionetas del Ejército, registrando los distintos momentos del operativo en cuestión que luego detallarían en una crónica respecto de "los primeros trabajos que se habían iniciado en el Hospital Penna, el Neuropsiquiátrico y Materno Infantil, con limpieza de yuyales, reconstrucción de paredes, muros y arreglos generales, tanto en el interior, como exterior de los mismos" (18).

Nuevamente la fotografía de oficiales en situación de obra y en tareas de construcción ilustraba el cuerpo de la noticia. Desde el epígrafe de la misma se especificaba que dentro del Centro Social Católico del barrio los militares se encontraban "dando forma a un local de 200 metros cubiertos para una guardería", resaltando que "toda la actividad se caracteriza por su organización y entusiasmo" (19).

Por otra parte, el operativo incluía ciertas tareas de registro poblacional y control de documentación anunciadas desde las "mesas de asesoramiento legal y técnico" del Registro Provincial de las Personas, de la Policía Federal, de la oficina de Migraciones y Acción Social de la Municipalidad. Al respecto, cabe mencionar que desde la reglamentación castrense sobre la "acción cívica" se concebían estos eventos de "acción cívica" como situaciones relevantes al momento de recabar información sobre la población civil para los servicios de inteligencia o bien auscultar impresiones, pareceres, humores sociales que pudieran ser traducidos luego en prácticas para generar adhesiones de la población. Dichos registros poblacionales podrían ser pensados en este marco de situación.

El tercer y último OS se realizó a finales de noviembre de 1981, en el barrio Luján. El Ejército trabajó de forma conjunta con miembros de la fuerza policial en este caso. Y siguiendo la lógica de los OS anteriores, el operativo implicó tareas de desmalezamiento de veredas y baldíos, trabajos con el personal de DOSBA; tareas de control social y poblacional desde la oficina de Migraciones y la Unidad Regional de Policía dedicada a asuntos de documentación extranjeros, asesoramiento sobre instalaciones de Gas del Estado y reparaciones de las mismas, instalaciones de luz con DEBA, limpieza de veredas y cordón cuneta, atención en clínica médica en diversas áreas.

Como una particularidad de este operativo, las fuerzas comunicaron desde los medios que en el marco de la tarea de "acción cívica" y desde las manifestaciones de los vecinos, habían hallado problemas en el barrio tras encontrar parcelas de tierras sin subdividir; los efectivos 
detallaron que "los vecinos han recibido boletos de compra-venta por terrenos que todavía están pagando, pero carecen de escrituras. Se encuentran en una situación legal débil que los imposibilita de recibir agua y luz" (20). Y nuevamente en este operativo se volvía a construir la imagen de consenso entre los vecinos respecto a las tareas de "acción cívica" realizadas, un consenso presentado desde gestos de agradecimiento y colaboración: "Numerosos vecinos testimoniaron su agradecimiento a los soldados, empleados y obreros de organismos oficiales que durante una semana participaron en tareas de mejoramiento, tendido de redes, líneas, caños y provisión de documentos" (21).

\section{Solidarios durante el día, engranajes del terror por la noche}

Los OS no nos hablan sólo de la articulación cívico-militar en las políticas públicas y visibles de la dictadura, en pos de construir una imagen "benefactora" de sus responsables.También nos dicen mucho respecto de las formas operativas desde las cuales se trató de incidir en el imaginario colectivo a partir del lugar otorgado a los periodistas, camarógrafos del diario LNP. Estos trabajadores de prensa resultaron testigos de las prácticas públicas de "acción cívica", protagonizadas incluso por algunos de los militares que estaban siendo responsables del engranaje represivo clandestino a nivel local. Responsables de la fase del terror que esos mismos medios de prensa silenciaron. Respecto de los nexos entre las tareas de "acción cívica", de acción psicológica y el accionar represivo presentaremos algunos puntos de análisis para pensar sus ejes de convergencia en la prensa de la época.

Dentro del esquema represivo de la subzona 51 , los secuestros, los traslados y las detenciones de personas a los centros clandestinos de la ciudad fueron realizados principalmente por un grupo operativo denominado "Agrupación Tropa" o "Equipo de Combate contra la Subversión". Esta agrupación estuvo al mando del teniente coronel Emilio Jorge Ibarra, a la vez dependiente del departamento III de Operaciones del Estado Mayor del V Cuerpo. A la misma fueron afectados muchos de los oficiales dentro del comando con el grado de subteniente entre los años 1976 y 1977. Estos oficiales, por lo general fueron traídos de otros lugares por fuera de Bahía Blanca pero dentro del marco de la zona sur que respondía al V Cuerpo.

La llamada "Agrupación Tropa" fue la responsable de muchas de las prácticas de terror en dictadura, principalmente (aunque no exclusivamente) tareas realizadas en horarios nocturnos. Tareas como los asesinatos que luego eran presentados a la sociedad bahiense desde escenas montadas, simulando "enfrentamientos". Los detalles del montaje aparecían en 
comunicados del Ejército que luego la prensa replicaba casi de manera textual. De esa forma los medios tuvieron un rol muy importante en el marco de tareas de acción psicológica (22).

Las tareas de acción cívica y acción psicológica aparecieron en las páginas del diario LNP de manera simultánea y conviviendo dentro de la superficie redaccional; las primeras buscaban la legitimación de las FFAA, las segundas la conformación de un "enemigo interno" entre otras cuestiones.

Por ejemplo, la edición del 15 de septiembre 1977 mostraba con cierta literalidad este doble juego. Desde un titular se anunciaba "Abaten a sediciosos" y se daba paso a la nota que plasmaba la acción psicológica ejercida por los comandos de Ejército. En ella se replicaba un comunicado del Comando de Zona I que refería a un supuesto enfrentamiento con "la banda de delincuentes subversivos marxistas autodenominada montoneros" (23). En realidad aludía a los casos de Adrián Carlovich, Roberto López y Juan Córdoba secuestrados varios meses antes, en junio de 1977 y más tarde fusilados por las fuerzas represivas (24). En la página inmediatamente anterior se consagraba al Ejército en una nota sobre el primer OS en la ciudad. Desde estos medios también fueron muy comunes las publicaciones que incluían relatos laudatorios sobre los militares y sus tareas contra el "enemigo subversivo". En estas notas, al igual que en las que se detallaban los OS, la imagen central era la del "ejército bueno", altruista y heroico. A modo de ejemplo, podemos mencionar una serie de notas que en el marco del $167^{\circ}$ aniversario del Ejército el 30 de mayo de 1977 difundieron la condecoración de algunos de los responsables del accionar represivo clandestino como fue el caso del subteniente Julián Corres; luego conocido torturador e interrogador del CCD local "La Escuelita" de Bahía Blanca. Desde esa serie de notas, LNP presentaba públicamente al subteniente como uno de los condecorados por el "heroico valor en combate". En esa oportunidad Osvaldo Azpitarte, a la sazón comandante del V Cuerpo, pronunciaba las palabras que daban lugar a los titulares del diario de aquel día: "Lucharemos hasta que haya desaparecido el último terrorista subversivo" (25). Como complemento de esa nota, aparecían también las imagen de los militares como protagonistas de los OS. Se presentaban por un lado las acciones "solidarias" y seguidamente las imágenes "heroicas" y de militares condecorados.

Por otro lado, vale señalar algunos de los trayectos de los militares protagonistas de estos OS. El primer OS estuvo a cargo el teniente coronel Rubén José Ferretti. A fines de los noventa, y en el marco de las declaraciones en los juicios por la Verdad en Bahía Blanca, quedó en evidencia la secuencia de mandos desde la cual operaban durante la dictadura los militares a nivel local. En su declaración, el teniente coronel Emilio Jorge Ibarra detallaba las tareas que realizaba desde la dependencia directa de su superior Ferretti, Jefe de la División Planes (26). Por otro lado, en el segundo OS uno de sus protagonistas fue Hugo Jorge Delmé. El Teniente 
Coronel Delmé estuvo en el cargo de jefe de Registro y Enlace del Departamento I Personal del Estado Mayor del V Cuerpo y de la subzona 51 entre 1976 y 1978 . Su rol dentro del engranaje represivo local fue el de atender a los cientos de familiares de detenidos desaparecidos de Bahía Blanca que se acercaban diariamente al V Cuerpo de Ejército para pedir información en las oficinas del comando. La tarea de Delmé fue la de negar sistemáticamente cualquier dato respecto de los paraderos de los desaparecidos cuando en realidad estaban sufriendo vejámenes y torturas en inmediaciones al Comando V Cuerpo de Ejército "La Escuelita", predio que Delmé conocía perfectamente. Años más tarde Delmé se defendería en el marco de los Juicios por la Verdad, aduciendo haber realizado meras "tareas administrativas" dentro del comando en la época. El ex militar falleció en abril de 2017 en Campo de Mayo donde cumplía su condena de cadena perpetua por crímenes de lesa humanidad.

\section{A modo de cierre}

El análisis sobre la cobertura de los llamados OS permite pensar los procesos comunicacionales y prácticas de búsqueda de consenso social durante la última dictadura militar. Reconocemos en ellos los intentos por envestir de legitimidad social el régimen y de cooptar voluntades a partir de la visibilidad de acciones concretas y la apelación a consignas patrióticas. Si bien resuena el ideario nacionalista, resulta inevitable también pensar la idea de "solidaridad" filiada a valores católicos en las tareas de bienestar social y desarrollo urbano/infraestructural que caracterizaron las prácticas de las fuerzas dentro de estos operativos.

En Bahía Blanca las tareas de "acción cívica" contaron con los aceitados vínculos de los militares con ciertos sectores de la sociedad y con los medios de prensa en particular. Esto resultó evidente en el trato mutuo y sobre todo en el estilo de la cobertura que realizó el diario LNP. Si bien el lugar que los medios de comunicación debían ocupar en los planes de "acción cívica" fue previsto por los mismos reglamentos castrenses, había en ese vínculo un grado de cooperación elocuente. LNP exhibía en sus páginas su lugar de "convidada de honor" para la comunicación de los operativos, instalándose públicamente en un lugar de testigo de los hechos y vocera de ellos "de primera mano".

El diario publicó no solo la imagen del ejército altruista, solidario; sino también la imagen de una fuerza que había logrado consumar vínculos de anuencia, demostrados por las imágenes de agradecimiento, cooperación y también solidaridad, en apariencia, despertadas en las 
comunidades barriales donde estos operativos se consumaron. LNP presentó una imagen de hermandad entre las comunidades, afectadas por los OS, y las fuerzas militares. Palabras como "adhesión", "colaboración", "solidaridad", o la expresión de "movilización cívico-militar" buscaron cimentar esa idea de consenso.

Sin embargo, consideramos que no debería perderse de vista el carácter de construcción de esa imagen de sociedad adherente y colaboradora publicitada desde este medio de prensa. Sobre todo en un contexto donde los medios fueron utilizados específicamente para tareas de "acción psicológicas". Al respecto resuenan las reflexiones de Baczko, cuando sostiene que:

\begin{abstract}
A lo largo de la historia, las sociedades se entregan a una invención permanente de sus propias representaciones globales, otras tantas ideas-imágenes a través de las cuales se dan una identidad, perciben sus divisiones, legitiman su poder o elaboran modelos formadores para sus ciudadanos tales como 'valiente guerrero', el 'buen ciudadano' el 'militante comprometido', etcétera. Estas representaciones de la realidad social (y no simples reflejos de ésta), inventadas y elaboradas con materiales tomados del caudal simbólico, tienen una realidad específica que reside en su misma existencia, en su impacto variable sobre las mentalidades y los comportamientos colectivos, en las múltiples funciones que ejercen en la vida social. De este modo, todo poder se rodea de representaciones, símbolos, emblemas, etc., que lo legitiman, lo engrandecen, y que necesita para asegurar su protección" (1999: 8).
\end{abstract}

La imagen de consenso que replicaba el diario era una imagen respecto a las prácticas específicas que se estaban concretando en los barrios en cuestión -y no de consenso generalizado con el régimen dictatorial en su conjunto-; esta es una cuestión que no debe perderse de vista. Sin embargo, esa presentación parcelada de los humores sociales finalmente terminaba operando al momento de construir imaginarios desde un medio de prensa.

Cabría interrogarnos respecto a la existencia de posibles tensiones latentes -por ejemplo- en las situaciones en las que el terror desbordaba el ocultamiento o se presentaba desde los violentos operativos en la vía pública ¿cómo pensar el posible abanico de actitudes sociales entre los testigos de operativos de secuestros, luego frente al despliegue de las fuerzas con "fines solidarios" en los mismos escenarios barriales? Esto dispara múltiples preguntas y somos conscientes que las mismas podrían comenzar a responderse solo desde estudios sobre la recepción de dichas prácticas de "acción cívica" entre las comunidades destinatarias, lo cual excede este artículo. Desde el mismo intentamos reponer tan solo algunos problemas para pensar las vías desde las cuales la dictadura buscó legitimarse, pero somos conscientes de la 
necesidad de mayores registros empíricos para realizar un acabado abordaje histórico respecto al impacto de dichas prácticas en los diversos sectores de la población.

\section{Notas}

(1) La ciudad de Bahía Blanca fue sede del Comando de la Subzona 51. Y como parte de la Zona V, la misma tenía jurisdicción en los partidos de González Chávez, Coronel Dorrego, Tres Arroyos, Adolfo Alsina, Guaminí, Coronel Suárez, Saavedra, Villarino, Puán, Tornquist, Coronel Pringles y Patagones, de la provincia de Buenos Aires; y los departamentos de Avellaneda, Pichi Mahuida, 25 de Mayo, Valcheta, San Antonio, Adolfo Alsina y Conesa, de la provincia de Río Negro.

(2) El diario La Nueva Provincia durante la época de la dictadura militar fue el principal diario de la ciudad Bahía Blanca y la zona, por estos años ya tenía una histórica trayectoria como medio de prensa en la ciudad que se remontaba a sus inicios a finales de siglo XIX. Desde el plano empresarial, este medio era propiedad de la familia Massot, y era dirigido por Diana Julio de Massot nieta de su fundador Enrique Julio. A mitad del siglo XX se trasformó en un multimedio hegemónico en la región dado que en abril 1958 incorporó la radio LU2 y en 1965 la empresa compró el primer canal de televisión de señal zonal, Canal 9 Telenueva.

(3) "desde el momento que el Ejército comienza la ocupación, a partir de 1810 del territorio situado al sur de Buenos Aires va ejecutando tareas del tipo que hoy encuadrarían en el término de ACCIÓN CíviCA. Los cuadros y los soldados aprendieron, como tareas complementarias de su quehacer militar a delinear y construir fortines, fuertes e incipientes poblaciones, a fabricar (...) a cavar zanjas defensivas y de regadío a construir iglesias, escuelas, cuarteles, casas, líneas telegráficas, caminos y como tarea importante el dictar clases en improvisadas escuelas" (Mayúscula en original) (Recchi, 1995: 223).

(4) Reglamento de Operaciones de Asuntos Civiles RC-19-1, 1966.

(5) Algunas de las prácticas de "acción cívica" que funcionaron bajo el horizonte del disciplinamiento social fueron reconstruidas por Daniel Lvovich y Laura Rodríguez con el caso de la conformación de la Gendarmería Infantil. Esta fue una experiencia limitada para niños varones de escuelas de frontera, desde la cual la fuerza de Gendarmería hacía explícita su voluntad de penetrar la lógica de funcionamiento y sociabilidad institucional dentro de la educación de niños y jóvenes, enmarcando la misma dentro de la "lucha antisubversiva" (Lvovich y Rodríguez, 2011).

(6) LNP, 14/09/1977.

(7) LNP, 14/09/1977.

(8) LNP, 14/09/1977.

(9) LNP, 14/09/1977.

(10) LNP, 14/09/1977

(11) LNP, 16/09/1977.

(12) LNP, 17/09/1977.

(13) LNP, 17/09/1977.

(14) LNP, 17/09/1977.

(15) Véase Zapata (2014 a) respecto a represión de familia Bustos, y operativos represivos hacia militantes de la JTP en Villa Libre durante la última dictadura militar.

(16) LNP, $7 / 5 / 1979$.

(17) LNP, 8/5/1979. 
(18) LNP, 8/5/1979.

(19) LNP, 8/5/1979.

(20) LNP, 26/11/1981.

(21) LNP, 26/11/1981.

(22) Desde 1968, y a partir del ReglamentoRC 5-2 Acción sicológica la "acción psicológica" fue definida por el discurso castrense como "un recurso permanente de la conducción que regula el empleo de métodos, procedimientos, técnicas y medios que influyen sobre el campo síquico de determinado público" (sic) Reglamento RC 5-2 Acción sicológica, 1968: $1-2$

(23) LNP, 15/09/1977.

(24) Cabe mencionar que hacia 1987 en el contexto de declaración indagatoria Adel Vilas $\left(2^{\circ}\right.$ Comandante del V Cuerpo y el Comandante de la subzona 51 durante 1976) proporcionó datos respecto a la relación existente entre periodistas y directivos del diario LNP y el V Cuerpo. A partir de su testimonio se conocieron detalles del entramado que caracterizó las tareas de "acción psicológica" que realizaban las fuerzas en coordinación con los medios de la familia Massot.

(25) LNP, 30/05/1977.

(26) Declaración en Juicio por la Verdad Bahía Blanca, audiencia del 07/12/99.

\section{Bibliografía}

Águila, G. (2006). Historia social, memoria y dictadura. El gran Rosario entre 1976 y 1983. (Tesis de doctorado). Rosario: Universidad Nacional de Rosario.

Águila, G. (2014). Disciplinamiento, control social y "acción sicológica" en la dictadura argentina. Una mirada a escala local: Rosario, 1976-1981. Revista RBBA, Vitória da Conquista, 3(01), pp. 211-239.

Baczko, B. (1999). Los imaginarios sociales. Memorias y esperanzas colectivas. Buenos Aires: Nueva Visión.

Blaustein, E. y Zubieta, M. (1998). Decíamos ayer. La prensa argentina bajo el proceso. Buenos Aires: Colihue.

Borrat, H. (1989). El periódico, actor político. Barcelona: Gili.

Borrelli, M. (2008). Hacia el "final inevitable". El diario Clarín y la "caída" del gobierno de Isabel Perón (1975-1976). (Tesis de Maestría). Buenos Aires: UBA, mimeo.

Borrelli, M. (2011). Voces y silencios: La prensa argentina durante la dictadura militar (19761983). Perspectivas de la Comunicación, 4(1). Universidad de la Frontera, Temuco, Chile, pp. 24-41.

Calvo Vicente, C. (1995). El concepto de consenso y su aplicación al estudio del régimen franquista. Revista Spagna Contemporánea, 7. 
Canelo, P. (2015). La importancia del nivel municipal para la última dictadura militar argentina. Un estudio a través de sus documentos reservados y secretos (1976-1983). Revista Historia 48(2), Santiago.

Divizenso, A. (2016). La "Acción Cívica" del Comando del II Cuerpo de Ejército. Un estudio sobre las relaciones cívico-militares en Rosario, 1960-1983. (Tesis de Maestría). UNGS, mimeo.

Franco, M. (2002). La "campaña anti argentina": la prensa, el discurso militar y la construcción de consenso. En Casali de Babot, J. y Grillo, M. V. (eds.). Derecha, fascismo y antifascismo en Europa y Argentina. Argentina: Universidad de Tucumán, pp. 195-225.

Lvovich, D. y Rodríguez, L. (2011). La Gendarmería Infantil durante la última dictadura. Quinto Sol, 15(1).

Lvovich, D. (2006). Dictadura y consenso. ¿Qué podemos saber? Revista Puentes, 6(17). La Plata: Comisión Provincial por la Memoria.

Mazzei, D. (2012). Bajo el poder de la caballería: el Ejército Argentino 1962-1973. Buenos Aires: Eudeba.

Montero, L. (2007). Memorias del golpe en La Nueva Provincia (1976-2006). Cernadas, M. y Marciese, J. (eds.). Cuestiones políticas, socioculturales del sudoeste bonaerense (pp.187-194). Bahía Blanca: Edi UNS.

Osuna, F. (2017). El hombre del año 2000. Actores, discursos y políticas hacia la infancia durante la dictadura (1976-1980). Revista Sociohistórica, 40.

Recchi, E. (1995). El ejército de Bahía Blanca: Acción y presencia. Guarnición de Ejército Bahía Blanca. Bahía Blanca: Fortaleza Protectora.

Saborido, J. y Borrelli, M. (coord.). (2011). Voces y silencios. La prensa argentina y la dictadura militar (1976-1983). Buenos Aires: Eudeba.

Varela, M. (2005). Los medios de comunicación durante la dictadura: entre la banalidad y la censura. Camouflage Comics. Censorship, Comics, Culture and the Arts. Recuperado de http://www.camouflagecomics.com/pdf/02_varela_es.pdf

Zapata, A. B. (2014a). Andamios de experiencias: Conflictividad obrera, vigilancia y represión en Argentina. Bahía Blanca, 1966-1976. (Tesis de Doctorado en Historia). La Plata: Universidad Nacional de La Plata, Facultad de Humanidades y Ciencias de la Educación, mimeo.

Zapata, A. B. (2014b). Como el herrero que machaca sobre el yunque hasta moldear la forma ideal. La Nueva Provincia y su construcción del llamado 'delincuente subversivo' (1975-1977). En Varela, M. y Borrelli, M. (eds). Dossier 07-Televisión, Dictadura y Transición en Argentina ReHiMe / Red de Historia de los Medios. Buenos Aires, 
pp.144-169.

Recuperado

de

http://www.rehime.com.ar/escritos/dossier/07prensaprov/dossier07-prensaprov-06.pdf 